\title{
Perception of indoor air quality (IAQ) by workers in underground shopping centers in relation to sick-building syndrome (SBS) and store type: a cross-sectional study in Korea
}

\author{
Jeonghoon Kim¹, Mijung Jang ${ }^{1}$, Kilyoung Choi ${ }^{2}$ and KyooSang Kim ${ }^{1 *}$ (D)
}

\begin{abstract}
Background: We examined the indoor air quality (IAQ) perceptions of workers and their relationships with the symptoms of sick-building syndrome (SBS) and store types in underground shopping centers.

Methods: In 2017, 314 store workers in nine underground shopping centers in Seoul, Korea, were assessed. The all participants' stores were partially opened onto a passage. Using questionnaires, they were asked about their demographics, job characteristics, 16 SBS symptoms, and seven IAQ perceptions. The SBS symptoms were categorized as skin, eye irritation, respiratory, or general. An IAQ perception score was calculated by adding the number of positive responses to each type of IAQ and categorized into three levels.

Results: The prevalence of SBS symptom groups in the previous month was $43.6 \%$ for skin symptoms, $62.4 \%$ for eye irritation symptoms, $65.6 \%$ for respiratory symptoms, and 64.7\% for general symptoms. Participants who perceived IAQ were more likely to have SBS symptoms (odds ratio: 1.81-7.84). The type of store employing the workers was associated with several IAQ perceptions. Subjects who worked in clothing and fashion-accessory stores were more likely to have high IAQ perception scores than those who worked in food services.

Conclusions: About half of the store workers in underground shopping centers had experienced SBS symptom groups in the previous month. The SBS symptom groups were associated with almost all IAQ perceptions. Because IAQ perception was associated with store type, studies of IAQ in working areas might need to improve store workers' health in underground shopping centers.
\end{abstract}

Keywords: Underground shopping center, Worker, Perception, Sick-building syndrome, Indoor air quality

\section{Background}

As defined by the World Health Organization in 1983 [1], sick-building syndrome (SBS) causes symptoms related to the indoor environment reported by occupants of office buildings. These symptoms include fatigue, headache, and irritation of the upper respiratory tract, eyes, nose, throat, and hand or facial skin $[1,2]$. SBS symptoms are associated with personal and environmental factors. Personal

\footnotetext{
* Correspondence: kyoosang@daum.net

${ }^{1}$ Department of Environmental Health Research, Seoul Medical Center, 156

Sinnae-ro, Jungnang-gu, Seoul 02053, Republic of Korea

Full list of author information is available at the end of the article
}

factors associated with SBS symptoms include female sex, history of allergies, anxiety, depression, and psychosocial work stress [3-5], while environmental factors include building characteristics (e.g., dampness and poor ventilation) $[6,7]$, indoor air pollution (e.g., volatile organic compounds (VOCs) and bioaerosols) [8, 9], and perceived indoor air quality (IAQ) such as odor and humidity perception $[10,11]$. However, the mechanism by which SBS symptoms are caused is not clear.

Subjective perception of IAQ, including odor perceptions and sensory irritation, is related to indoor air pollutants, such as VOCs and nitrogen oxides [12]. Sources

(c) The Author(s). 2019 Open Access This article is distributed under the terms of the Creative Commons Attribution 4.0 International License (http://creativecommons.org/licenses/by/4.0/), which permits unrestricted use, distribution, and reproduction in any medium, provided you give appropriate credit to the original author(s) and the source, provide a link to the Creative Commons license, and indicate if changes were made. The Creative Commons Public Domain Dedication waiver (http://creativecommons.org/publicdomain/zero/1.0/) applies to the data made available in this article, unless otherwise stated. 
of odors in indoor environments include human body odor, secondhand smoke, bio-odorants (e.g., mold and animal-derived materials), and cosmetics [13]. Sensory irritation of the eyes and airways may be due to airborne compounds stimulating the skin or mucosal tissues, which is often described as "dryness." Sensory irritation and odor perception are often experienced simultaneously.

Most SBS studies have been conducted in office buildings $[9,14,15]$. However, in our knowledge, studies regarding SBS symptoms of workers in underground spaces in other countries have not been well reported. Worldwide, underground spaces are being used increasingly for various purposes, such as transportation systems and commercial facilities [16]. In metropolitan centers, underground shopping areas are often crowded with shoppers, passengers, workers, and employees.

Although the IAQ in underground shopping centers in Korea is regulated by the Indoor Air Quality Management Act, workers in specific sections or semi-open stores might be exposed to different levels of indoor air pollution due to different emission sources in each store [17]. One study reported that the carbon dioxide $(\mathrm{CO})$, formaldehyde $(\mathrm{HCHO})$, and total volatile organic compound (TVOC) concentrations differed significantly $(P<0.05)$ in different merchandise sections in nine department stores in China [18]. Thus, store employees who spend large amounts of time in stores could be exposed significantly of such pollutants.

In the present study, we investigated the subjective health and IAQ of workers in underground shopping stores. The purposes of this study was to examine the relationships between SBS symptoms and the IAQ perceptions of workers, as well as the associations between IAQ perception and store type in underground shopping areas.

\section{Methods}

\section{Study site and participants}

Seoul, the capital of the Republic of Korea, had 29 underground shopping centers in 2017. We selected nine underground shopping centers based on our preliminary study conducted in March to April (spring season), 2017 [19]. Briefly, several air pollutants (e.g., CO, particulate matter, suspended bacteria, and etc.) were measured in one to three points at the passages in 26 of the 29 underground shopping centers to examine IAQ in these centers. The preliminary study revealed that almost all air pollutants did not exceed the maintenance or recommended standards for Korean IAQ in 2017.

In this study, we focused on prevalence and associated factors of SBS symptoms and perceived IAQ of store workers in underground shopping centers. Based on the preliminary study, we ranked the 26 underground shopping centers according to levels of each air pollutant and scored them to classify three different groups of underground shopping centers by low, middle, and high scores of air pollution [19]. In each group, three underground shopping centers with similar scores were selected.

The selected nine underground shopping centers had a trained interviewer visit stores in each underground shopping center in September (late summer season), 2017. At that time, the nine underground shopping centers had 1143 stores, ranging from 53 to 520 stores per center and their net floor area was more than $3000 \mathrm{~m}^{2}$ in each centers [20]. IAQ in these underground shopping centers was controlled by heating, ventilating, and air conditioning (HVAC) system.

In each shopping center, we selected approximately 35 stores ranged from 33 to 36 stores, most of which opened onto a passage. Thus, indoor air might share between stores and passages. The interviewers chose store workers with similar sex and age ratios from across the nine underground shopping centers because we considered sex and age of store workers might be associated with SBS symptoms. However, we did not have any prior knowledge of the SBS symptoms, IAQ perceptions, or other demographic and job characteristics of these workers. One worker in each store was asked to complete a self-administered questionnaire displayed on a tablet computer. In total, 314 workers participated.

\section{Measurements}

The questionnaire included information on demographic and job characteristics, SBS symptoms, and IAQ perceptions (Additional file 1: Table S1). The demographic characteristics included sex, age, education level, and smoking status. The job characteristics included the name of the underground shopping center, length of employment, hours worked per day, floor level, store remodeling status, and store type. We categorized the stores into four different groups with similar characteristics: food service (e.g., restaurants, cafes, and bakeshops), clothing (e.g., clothing stores, clothing repair shops, and bedclothes shops), fashion accessories (e.g., shoe, bag, and briefcase shops), and others (e.g., office, electronic products, and cosmetic shops).

To determine subjective health status, we used 16 SBS questions based on a modified version of the National Institute for Occupational Safety and Health Indoor Air Quality and Work Environment Symptoms Survey (Additional file 1: Table S2). Similar SBS question items have been used in previous studies [14, 21]. The SBS question was "Have you experienced the following symptom while working in the underground shopping center in the last month?" For each SBS symptom, the participants chose one of the following options: "never," "rarely," "neutral," "sometimes," and "frequently." We deemed that they had the SBS symptom if they answered "sometimes" or "frequently." The 16 symptoms were 
categorized into the following four SBS group based on clinical symptom characteristics: (1) Skin symptoms included "skin dryness or itching." (2) Eye irritation symptoms included "dry, itching, or irritated eyes" and "tired or strained eyes." (3) Respiratory symptoms included "stuffy or runny nose," "cough," "sneezing," "sore or dry throat," "wheezing," and "shortness of breath or chest tightness." (4) General symptoms included "nausea or upset stomach," "headache," "tiredness, fatigue or drowsiness," "nervousness," "difficulty remembering things or concentrating," "dizziness or lightheadedness," and "feeling depressed." Similar groupings of SBS symptoms have been reported [10, 11, 14]. Each symptom group was defined as having symptoms if at least one of the SBS symptoms for that group was reported.

We used perceived IAQ, including odor and humidity perceptions (Additional file 1: Table S3). The odor and humidity perception had been used as qualitative indicators of IAQ in previous studies $[10,11]$. The IAQ perception questions were "Have you experienced the following perception while working in the underground shopping center in the last month: (1) stuffy odor; (2) unpleasant odor; (3) pungent odor; (4) moldy odor; (5) tobacco smoke odor; (6) humid air; or (7) dry air?" For each IAQ perception, we used a five-item scale, choosing one of the following options: "never," "rarely," "neutral," "sometimes," and "frequently." When a participant answered "sometimes" or "frequently" for each IAQ perception, we considered it a "yes" response ( $\operatorname{code}=1$ ), while the others were considered a "no" response $($ code $=0)$. The IAQ perception score was calculated by adding the number of positive responses for each IAQ and ranged from 0 to 7 . Then, the IAQ perception score was categorized into three levels with similar proportions: category 0 , score 0 out of 7 "yes" answers; category 1, score 1 or 2 out of 7 "yes" answers; and category 2, score $>2$ out of 7 "yes" answers. Similar categorization has been used in a previous study [11].

\section{Statistical analysis}

The chi-square test was used to compare the prevalence of the SBS symptom groups with the workers' demographic and job characteristics. Because all of the underground shopping centers were located at first-basement levels and only $3 \%$ of the stores ( 9 of 314 stores) had been remodeled within 6 months, these factors were not used as variables. Although the nine underground shopping centers were classified by three different score groups of air pollution, we did not use this variable because the groups of underground shipping centers were not associated with any of SBS symptoms or IAQ perception of store workers (data not shown). Tables S1 and S2 present the relationships between IAQ perception or categorized IAQ perception and the workers' demographic and job characteristics, respectively (Additional file 2). Spearman correlation was used to assess the relationships among the IAQ perception index. Multivariable logistic regression models were used to examine the relationships between SBS symptom groups and IAQ perception or to determine the relationships between IAQ perception and types of store controlling for workers' demographics and other job characteristics. We further examined the relationships between SBS symptoms and store types of workers in underground shopping centers using multivariable logistic regression models (Additional file 2: Table S3). Potential variables identified by the chi-square test $(P<0.1)$ were included in the final model. Although several SBS symptoms or IAQ perceptions were not associated with sex, age, smoking status, and store type in the chi-square test, we included these factors in the multivariable logistic models because these variables could affect the observed associations. Because the categorized IAQ perceptions levels were ordinal, the proportional odds assumption in the regression models for IAQ perception was tested using the score test to confirm or reject the assumption. The odds ratio (OR) for the prevalence of SBS symptom groups or IAQ perception of workers was reported with the $95 \%$ confidence interval (CI). A $P$-value of 0.05 was deemed significant in all analyses. SAS 9.4 software (SAS Institute, Cary, NC, USA) was used for all statistical analyses.

\section{Results}

The average age of the 314 store workers was $47 \pm 13$ years and 58\% were female. The prevalence of the 16 SBS symptoms in the store workers in the previous month ranged from 12.7 to $57.6 \%$ (Table 1). For the SBS symptom groups, the prevalence of SBS symptoms was $43.6 \%$ for skin symptoms, $62.4 \%$ for eye irritation symptoms, $65.6 \%$ for respiratory symptoms, and $64.7 \%$ for general symptoms.

Table 2 shows the prevalence of SBS symptom groups in the previous month according to demographic and job characteristics. The prevalence of skin, eye irritation, respiratory, and general symptoms differed with several demographic and job characteristics. Particularly, the prevalence of eye irritation and general symptom groups were significantly higher in female workers than in men. Associations SBS symptoms with store type of the workers in the multivariable logistic regression models are presented in Table S3 (Additional file 2).

Among the store workers, dry air was the most perceived IAQ perception (46.2\%), followed by stuffy odor (34.4\%), unpleasant odor $(28.0 \%)$, pungent odor (22.0\%), humid air (19.1\%), tobacco smoke odor (18.2\%), and moldy odor (16.6\%). Table 3 shows the cross-correlations between any two IAQ perceptions. All IAQ perceptions were significantly correlated with each other, except for the correlation between humid air and tobacco smoke odor.

Table 4 shows the results of the multivariable logistic regression analyses of all four SBS symptom groups for 
Table 1 Prevalence of 16 sick-building-syndrome symptoms in store workers in underground shopping centers in the previous month

\begin{tabular}{lll}
\hline Group & Symptom & Yes (\%) \\
\hline Skin & Skin dryness or itching & $137(43.6)$ \\
Respiratory & Dry, itching, or irritated eyes & $167(53.2)$ \\
& Tired or strained eyes & $162(51.6)$ \\
& Stuffy or runny nose & $123(39.2)$ \\
& Sough & $116(36.9)$ \\
& Sore or dry throat & $144(45.9)$ \\
& Wheezing & $151(48.1)$ \\
General & Shortness of breath or chest tightness & $49(15.6)$ \\
& Nausea or upset stomach & $52(16.6)$ \\
& Headache & $115(36.6)$ \\
& Tiredness, fatigue, or drowsiness & $181(57.6)$ \\
& Nervousness & $115(36.6)$ \\
& Difficulty in remembering things or & $90(28.7)$ \\
& in concentrating & $61(19.4)$ \\
& Dizziness or lightheadedness & $40(12.7)$ \\
\hline
\end{tabular}

the workers according to IAQ perceptions. After adjusting for demographic and job characteristics, most SBS symptoms were significantly associated with all IAQ perceptions. The ORs of the SBS symptoms for IAQ perceptions ranged from 1.81 to 8.07. Furthermore, the relationships between all of the SBS symptom groups and the categorized IAQ perception score were dose-dependent ( $P$ for trend $<0.001$ ). Slightly higher effects of IAQ perceptions on SBS symptoms were observed in the multivariable logistic regression analyses without adjustment for store types (Additional file 2: Table S4).

The relationships between IAQ perception and store type were examined in multivariable logistic analysis adjusting for demographic and job characteristics (Table 5). Participants who worked in clothing $(\mathrm{OR}=3.47$, $95 \% \mathrm{CI}=1.10-10.92)$ and fashion accessory $(\mathrm{OR}=4.02$, $95 \% \mathrm{CI}=1.20-13.44)$ stores were more likely to perceive stuffy odors than those who worked in food services. Participants who worked in clothing $(\mathrm{OR}=7.28,95 \% \mathrm{CI}=$ 1.64-32.26) and fashion accessory $(\mathrm{OR}=5.44,95 \% \mathrm{CI}=$ 1.15-25.77) stores were more likely to perceive unpleasant odors than those who worked in food services. Participants who worked in fashion-accessory stores $(\mathrm{OR}=$ $13.11,95 \% \mathrm{CI}=1.63-105.35$ ) were more likely to perceive a moldy odor than those who worked in food services. Participants who worked in clothing $(\mathrm{OR}=2.74,95 \% \mathrm{CI}=$ 1.11-6.78) and fashion accessory $(\mathrm{OR}=3.46,95 \% \mathrm{CI}=$ 1.28-9.35) stores were more likely to perceive dry air than those who worked in food services. Participants who worked in clothing $(\mathrm{OR}=2.92,95 \% \mathrm{CI}=1.33-6.38)$ and fashion accessory $(\mathrm{OR}=3.25,95 \% \mathrm{CI}=1.37-7.71)$ stores were more likely to have high IAQ perception score categories than those who worked in food services. However, pungent odor, tobacco smoke odor, and humid air were not associated with store type.

\section{Discussion}

Investigation of $16 \mathrm{SBS}$ symptoms for store workers in underground shopping centers revealed that about one to six out of ten workers experienced at least one SBS symptom at their stores in the previous months. The four SBS symptom groups of store workers in underground shopping centers were associated with almost all IAQ perceptions. When IAQ perceptions were dependent variables, several IAQ perceptions were significantly associated with store types of the workers. Particularly, workers in clothing or fashion-accessory stores were more likely to experience several IAQ perceptions than other types of stores. Overall, their effects on IAQ perceptions were higher for workers in fashion-accessory stores than those in clothing stores.

For each SBS symptom group, about half of the workers in stores in underground shopping centers experienced at least one SBS symptom in the previous month. Of the SBS symptom groups, the prevalence of respiratory symptoms was highest. Overall, the percentage of women in all SBS symptom groups was higher than for men, similar to previous studies $[3,11]$. This might be because women are more sensitive to SBS symptoms than men [8]. Age, hours worked per day, and store type were associated with several SBS symptom groups.

Workers most often perceived dry air, followed by stuffy odor, unpleasant odor, pungent odor, humid air, tobacco smoke odor, and moldy odor. Most IAQ perceptions were significantly correlated with each other. The correlation was highest between unpleasant and pungent odors. The correlation coefficients between stuffy odor and unpleasant or pungent odors were greater than 0.5 , while the other correlation coefficients were less than 0.5 . This indicated that different correlation coefficients (low or high) with each other reflected different aspects of the perceived IAQ. Similar findings have been reported when the parents of children reported IAQ perceptions for the home environment in China [22].

Almost all IAQ perceptions were significantly associated with SBS symptom groups in the multivariable logistic analyses. Overall, the IAQ perceptions had higher ORs for respiratory symptoms than for skin, eye irritation, or general symptoms of workers. These trends were consistent with the relationships between SBS symptoms and categorized IAQ perception scores. Dose-dependent relationships were observed between the SBS symptoms and categorized IAQ perception scores. Our findings indicated that IAQ perception might be associated with 
Table 2 Prevalence of sick-building-syndrome symptoms according to the demographic and job characteristics of store workers in underground shopping centers

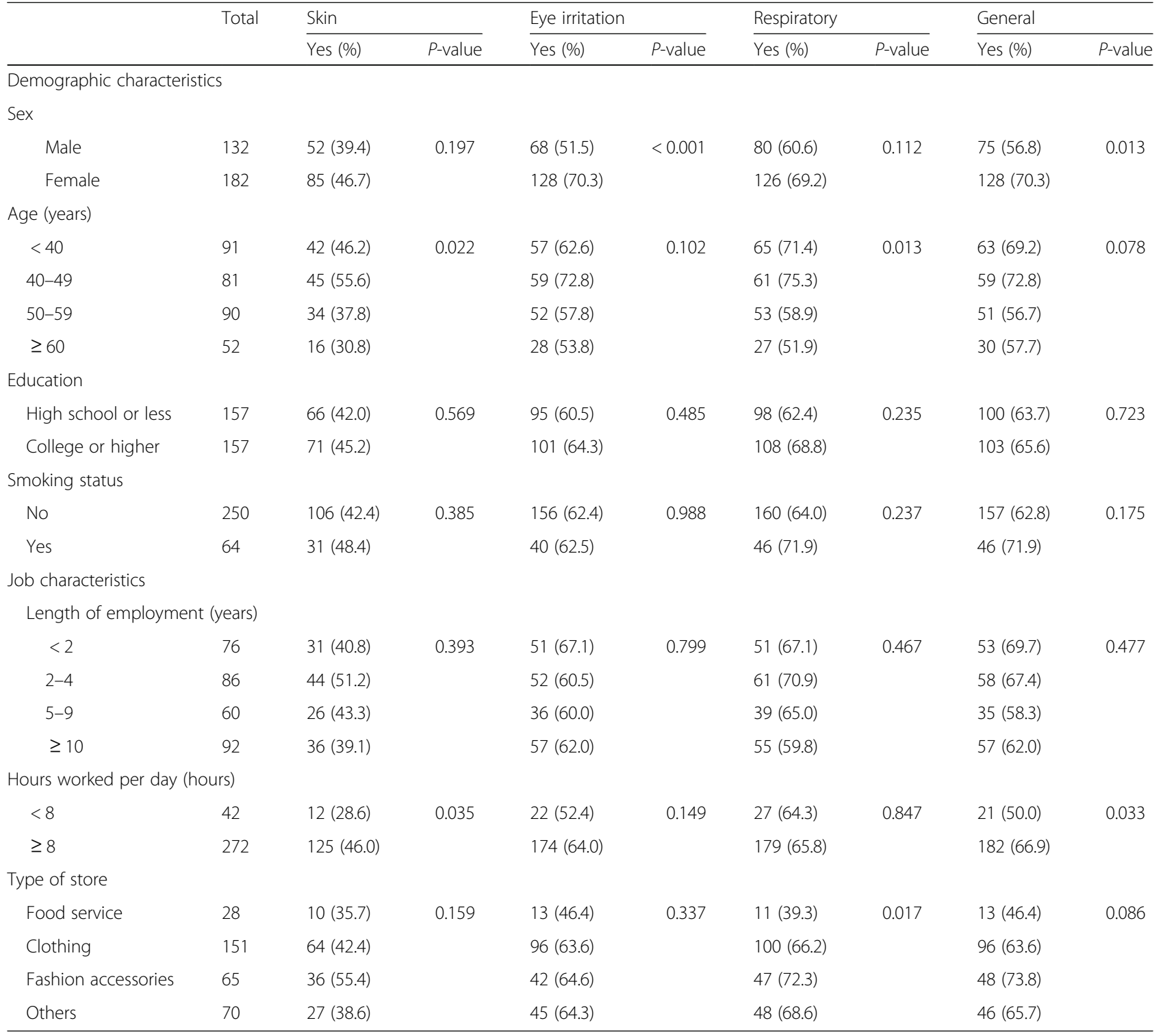

Table 3 Spearman correlation coefficients among indicators of indoor air quality perceived by workers in underground shopping centers $(n=314)$

\begin{tabular}{|c|c|c|c|c|c|c|c|}
\hline & Stuffy odor & Unpleasant odor & Pungent odor & Moldy odor & Tobacco smoke odor & Dry air & Humid air \\
\hline Stuffy odor & 1.00 & & & & & & \\
\hline Unpleasant odor & $0.67^{* * *}$ & 1.00 & & & & & \\
\hline Pungent odor & $0.60^{* * *}$ & $0.71^{* * *}$ & 1.00 & & & & \\
\hline Moldy odor & $0.42^{* * *}$ & $0.31^{* * *}$ & $0.38^{* * *}$ & 1.00 & & & \\
\hline Tobacco smoke odor & $0.23^{* * *}$ & $0.28^{* * *}$ & $0.29^{* * *}$ & $0.12^{*}$ & 1.00 & & \\
\hline Dry air & $0.19^{* * *}$ & $0.13^{*}$ & $0.14^{*}$ & $0.22^{* * *}$ & $0.18^{* *}$ & 1.00 & \\
\hline Humid air & $0.14^{*}$ & $0.22^{* * *}$ & $0.23^{* * *}$ & $0.15^{* *}$ & 0.07 & $0.23^{* * *}$ & 1.00 \\
\hline
\end{tabular}


Table 4 Relationships between sick-building-syndrome symptoms and indoor air quality (IAQ) perceptions of workers in underground shopping centers

\begin{tabular}{|c|c|c|c|c|}
\hline & Skin $^{a}$ & Eye irritation ${ }^{b}$ & Respiratory $^{b}$ & General $^{a}$ \\
\hline & OR (95\% Cl) & OR $(95 \% \mathrm{Cl})$ & OR $(95 \% \mathrm{Cl})$ & OR $(95 \% \mathrm{Cl})$ \\
\hline \multicolumn{5}{|l|}{ Stuffy odor } \\
\hline No & 1.00 & 1.00 & 1.00 & 1.00 \\
\hline Yes & $2.89(1.73-4.83)^{* * *}$ & $6.39(3.40-12.01)^{* * *}$ & $4.79(2.56-8.97)^{* * *}$ & $6.03(3.12-11.63)^{* * *}$ \\
\hline \multicolumn{5}{|c|}{ Unpleasant odor } \\
\hline No & 1.00 & 1.00 & 1.00 & 1.00 \\
\hline Yes & $2.08(1.23-3.51)^{* *}$ & $4.06(2.15-7.67)^{* * *}$ & $4.00(2.05-7.81)^{* * *}$ & $4.29(2.19-8.41)^{* * *}$ \\
\hline \multicolumn{5}{|l|}{ Pungent odor } \\
\hline No & 1.00 & 1.00 & 1.00 & 1.00 \\
\hline Yes & $3.07(1.72-5.50)^{* * *}$ & $5.16(2.44-10.89)^{* * *}$ & $7.33(3.09-17.4)^{* * *}$ & $4.46(2.11-9.42)^{* * *}$ \\
\hline \multicolumn{5}{|l|}{ Moldy odor } \\
\hline No & 1.00 & 1.00 & 1.00 & 1.00 \\
\hline Yes & $2.29(1.19-4.41)^{*}$ & $3.65(1.64-8.13)^{* *}$ & $3.81(1.59-9.09)^{* *}$ & $2.93(1.28-6.71)^{*}$ \\
\hline \multicolumn{5}{|c|}{ Tobacco smoke odor } \\
\hline No & 1.00 & 1.00 & 1.00 & 1.00 \\
\hline Yes & $1.81(0.99-3.32)$ & $2.45(1.21-4.99)^{*}$ & $4.04(1.78-9.13)^{* * *}$ & $3.29(1.54-7.02)^{* *}$ \\
\hline \multicolumn{5}{|l|}{ Dry air } \\
\hline No & 1.00 & 1.00 & 1.00 & 1.00 \\
\hline Yes & $5.14(3.07-8.60)^{* * *}$ & $7.07(3.99-12.50)^{* * *}$ & $7.84(4.28-14.35)^{* * * *}$ & $6.21(3.47-11.11)^{* * *}$ \\
\hline \multicolumn{5}{|l|}{ Humid air } \\
\hline No & 1.00 & 1.00 & 1.00 & 1.00 \\
\hline Yes & $2.16(1.18-3.93)^{*}$ & $2.40(1.22-4.71)^{*}$ & $3.11(1.47-6.58)^{* *}$ & $2.37(1.18-4.76)^{*}$ \\
\hline \multicolumn{5}{|c|}{ Categorized IAQ perception score ${ }^{c}$} \\
\hline Category 0 & 1.00 & 1.00 & 1.00 & 1.00 \\
\hline Category 1 & $5.62(2.85-11.06)^{* * *}$ & $4.96(2.68-9.18)^{* * *}$ & $5.26(2.83-9.76)^{* * *}$ & $3.80(2.07-6.98)^{* * *}$ \\
\hline Category 2 & $9.92(4.91-20.05)^{* * *}$ & $19.33(8.75-42.71)^{* * *}$ & $19.39(8.47-44.39)^{* * *}$ & $12.89(5.96-27.9)^{* * *}$ \\
\hline$p$-for trend & $<0.001$ & $<0.001$ & $<0.001$ & $<0.001$ \\
\hline
\end{tabular}

SBS symptoms of store workers in underground shopping centers. Similar associations have been reported in previous studies. The sensation of dryness among office workers in northern Sweden was associated with SBS symptoms [23]. Perceived stuffy air, dry air, and unpleasant odor were significantly associated with several SBS symptom of workers in public and private companies in Italy [5]. A study conducted in Chongqing, China, reported that IAQ perceptions of parents of children at home were associated with SBS symptoms [10].

Store type was associated with several IAQ perceptions, especially stuffy odor, unpleasant odor, moldy odor, dry air, and categorized IAQ perception scores. Particularly, people who worked in clothing or fashion-accessory stores were more likely to experience several IAQ perceptions and categorized IAQ perception scores than those who worked in food services. Overall, the effects on IAQ perception or categorized IAQ perception score were higher for workers in fashion-accessory stores than those in clothing stores. This suggests that the IAQ may be lower in fashionaccessory stores than in other store types.

The IAQ of stores in underground shopping centers might differ according to the merchandise sold in that store. Fabrics and leather merchandise can contain formaldehyde-based adhesives [24]. The fashion-accessory stores in the present study sold mainly leather products, including shoes, bags, wallets, and backpacks. A study in China reported that when the $\mathrm{HCHO}$ and TVOC concentrations were measured in food, clothing, electronic products, leather products, and cosmetics zones in nine 
Table 5 Relationships between perceived indoor air quality (IAQ) and type of store for workers in underground shopping centers

\begin{tabular}{|c|c|c|}
\hline IAQ perception & Type of store & OR $(95 \% \mathrm{Cl})$ \\
\hline \multirow[t]{4}{*}{ Stuffy odor ${ }^{a}$} & Food service & 1.00 \\
\hline & Clothing & $3.47(1.10-10.92)^{*}$ \\
\hline & Fashion accessories & $4.02(1.20-13.44)^{*}$ \\
\hline & Others & $2.54(0.75-8.59)$ \\
\hline \multirow[t]{4}{*}{ Unpleasant odor $^{\mathrm{b}}$} & Food service & 1.00 \\
\hline & Clothing & $7.28(1.64-32.26)^{* *}$ \\
\hline & Fashion accessories & $5.44(1.15-25.77)^{*}$ \\
\hline & Others & $4.64(0.98-21.94)$ \\
\hline \multirow[t]{4}{*}{ Pungent odor ${ }^{a}$} & Food service & 1.00 \\
\hline & Clothing & $1.75(0.55-5.55)$ \\
\hline & Fashion accessories & $1.76(0.51-6.05)$ \\
\hline & Others & $1.30(0.37-4.54)$ \\
\hline \multirow[t]{4}{*}{ Moldy odor ${ }^{b}$} & Food service & 1.00 \\
\hline & Clothing & $5.32(0.68-41.65)$ \\
\hline & Fashion accessories & $13.11(1.63-105.35)^{* *}$ \\
\hline & Others & $4.29(0.51-36.03)$ \\
\hline \multirow[t]{4}{*}{ Tobacco smoke odor ${ }^{b}$} & Food service & 1.00 \\
\hline & Clothing & $1.60(0.51-4.96)$ \\
\hline & Fashion accessories & $1.25(0.35-4.45)$ \\
\hline & Others & $1.38(0.40-4.79)$ \\
\hline \multirow[t]{4}{*}{ Dry air ${ }^{b}$} & Food service & 1.00 \\
\hline & Clothing & $2.74(1.11-6.78)^{*}$ \\
\hline & Fashion accessories & $3.46(1.28-9.35)^{*}$ \\
\hline & Others & $1.97(0.74-5.24)$ \\
\hline \multirow[t]{4}{*}{ Humid air } & Food service & 1.00 \\
\hline & Clothing & $0.40(0.16-1.03)$ \\
\hline & Fashion accessories & $0.71(0.26-2.00)$ \\
\hline & Others & $0.80(0.29-2.17)$ \\
\hline \multirow{4}{*}{$\begin{array}{l}\text { Categorized IAQ } \\
\text { perception score }{ }^{b, c}\end{array}$} & Food service & 1.00 \\
\hline & Clothing & $2.92(1.33-6.38)^{* *}$ \\
\hline & Fashion accessories & $3.25(1.37-7.71)^{* *}$ \\
\hline & Others & $2.05(0.88-4.78)$ \\
\hline
\end{tabular}

${ }^{*} P<0.05 ;{ }^{* *} P<0.01$

${ }^{a} \mathrm{OR}$ was adjusted for sex, age, smoking status, and hours worked per day

${ }^{\mathrm{b}} \mathrm{OR}$ was adjusted for sex, age, and smoking status

'Proportional odds assumption in the cumulative logistic model was met $(P=0.78)$

underground malls, the $\mathrm{HCHO}$ concentrations were generally higher (up to $300 \mu \mathrm{g} / \mathrm{m}^{3}$ ) in the leather zone than in the other zone types [25]. In that study, the TVOC concentrations were highest in food zones, followed by cosmetic and leather zones. In our study, those who worked in food stores had the lowest ORs on IAQ perception. The food stores we studied included restaurants, cafes, and bakeshops. Although restaurants might have emission sources due to cooking activity, cafes and bakeshops might not have significant emission sources. Therefore, the IAQ perception of the food store workers would not be significantly affected.

This is first study to examined SBS symptoms in store workers in underground shopping areas and their relationships with IAQ perception. We also examined the relationships between the workers' IAQ perceptions and store type.

This study had several limitations. Because it was cross-sectional, we could not infer that IAQ perceptions were causally associated with the workers' SBS symptoms. Moreover, because we selected participants in nine underground shopping centers, it might not have been representative of all workers in underground shopping centers in Seoul. Selection of the nine underground shopping centers and 33 to 36 store workers considering sex and age ratios in each center might have biases. Previous studies reported that sex and age was associated with SBS symptoms of workers or occupants in indoor places $[3,8]$. Thus, controlling the sex and age ratios across the underground shopping centers might reduce variation of SBS symptoms in different underground shopping centers.

Another limitation was that the participants might have variation of reporting SBS symptoms and IAQ perceptions depending on their sensitivity because we did not use objective methods such as medical examinations by physicians or measurement of IAQ with monitors in each store. Prevalence of SBS symptoms of store workers in underground shopping centers might be excessively estimated because we considered they had SBS symptoms if they answered "sometimes" or "frequently." Workers with negative disposition might report more SBS symptoms or signs of discomfort for the work environment. Furthermore, recall bias might have affected the prevalence of personal SBS symptoms or IAQ perception. However, the recall bias for SBS symptoms and IAQ perception might not have been a critical issue in our study, since the recall period was short (the previous month).

Although we included several demographic and job factors, there might have been residual confounding of SBS symptoms or IAQ perceptions. Another study reported that personal factors such as a history of allergic disease, anxiety, depression, and psychosocial work stress were risk factors for SBS symptoms [3-5]. Environmental factors, including dampness and ventilation, might also be associated with SBS symptoms or IAQ perception [6, 7]. Unfortunately, we did not measure these factors.

The IAQ in underground shopping centers in Korea is regulated by the Indoor Air Quality Management Act. According to the Act, the IAQ should be measured at a passage. The Act was mainly focused on the shoppers or passengers rather than on store workers. In the Korean Occupational Safety and Health Act, there was limited 
policy for management of IAQ in such small store in the underground shopping centers. We found that a large percentage of the store workers had SBS symptoms, which were associated with type of stores or IAQ perception. The IAQ perception of the store workers was associated with the types of stores. Further research should investigate IAQ using an objective method at the working-area-level in underground shopping centers.

\section{Conclusion}

A total of 314 store workers in nine underground shopping centers in Seoul participated. About half of these workers had experienced SBS symptom groups in the previous month. The SBS symptom groups were associated with all IAQ perceptions. When the IAQ perceptions were dependent variables, most IAQ perceptions were associated with store type. Those working in fashion-accessory stores were more likely to experience stuffy, unpleasant, and moldy odors, and dry air, and were more likely to have higher categorized IAQ perception scores than those who worked in food services. Our findings suggested that workers in fashion-accessory stores might be exposed to low IAQ.

\section{Additional files}

Additional file 1: Table S1. Ten items of demographic and job information. Table S2. Sixteen items of sick-building-syndrome symptoms. Table S3. Seven items of indoor air quality perception. (DOCX $27 \mathrm{~kb}$ )

Additional file 2: Table S1. Percentages of indoor air quality perception according to demographic and job characteristics of store workers in underground shopping centers. Table S2. Categorized indoor air quality (IAQ) perception scores according to the demographic and job characteristics of store workers in underground shopping centers. Table S3. Relationships between sick-building-syndrome (SBS) symptoms and type of store for workers in underground shopping centers. Table S4. Relationships between sick-building-syndrome symptoms and indoor air quality (IAQ) perceptions of workers in underground shopping centers without adjustment for type of stores in the multiple logistic regression model. (DOCX $39 \mathrm{~kb}$ )

\section{Abbreviations}

Cl: Confidence interval; CO: Carbon monoxide; HVAC: Heating, ventilating, and air conditioning; $\mathrm{HCHO}$ : Formaldehyde; IAQ: Indoor air quality; OR: Odds ratio; SBS: Sick-building syndrome; TVOC: Total volatile organic compound; VOCs: Volatile organic compounds

\section{Acknowledgements}

The authors appreciate Seoul Metropolitan Government and Seoul Medical Center for their support.

\section{Funding}

This study was supported by the Seoul Medical Center, Korea (17-A04). The sponsor played no role in the design, in the collection, analysis, and interpretation of data, in the writing of the manuscript, or in the decision to submit the manuscript for publication. The article contents are solely the responsibility of the authors and do not necessarily represent the official views of the sponsor.

\section{Availability of data and materials}

The datasets analyzed in the current study are available from the corresponding author upon reasonable request.

\section{Authors' contributions}

JK took primary responsibility for writing the paper and data analysis. MJ collected and managed the data. JK, KC, and KK contributed to the conceptualization of the study. All authors approved the final version of the manuscript.

\section{Ethics approval and consent to participate}

The study was approved by the institutional review board of Seoul Medical Center (IRB no. 2017-07-002). All of the workers participated voluntarily and provided written informed consent.

\section{Consent for publication}

Not applicable.

\section{Competing interests}

The authors declare that they have no competing interests.

\section{Publisher's Note}

Springer Nature remains neutral with regard to jurisdictional claims in published maps and institutional affiliations.

\section{Author details}

${ }^{1}$ Department of Environmental Health Research, Seoul Medical Center, 156 Sinnae-ro, Jungnang-gu, Seoul 02053, Republic of Korea. ${ }^{2}$ Department of Chemical Biotechnology, Seokyeong University, 124 Seogyeong-ro Seongbuk-gu, Seoul 02173, Republic of Korea.

Received: 14 January 2019 Accepted: 15 May 2019

Published online: 23 May 2019

\section{References}

1. WHO. Indoor air pollutants: exposure and health effects. In: WHO regional Office for Europe; 1983.

2. Redlich CA, Sparer J, Cullen MR. Sick-building syndrome. Lancet. 1997; 349(9057):1013-6.

3. Runeson R, Wahlstedt K, Wieslander G, Norback D. Personal and psychosocial factors and symptoms compatible with sick building syndrome in the Swedish workforce. Indoor Air. 2006;16(6):445-53.

4. Bakke JV, Moen BE, Wieslander G, Norbäck D. Gender and the physical and psychosocial work environments are related to indoor air symptoms. J Occup Environ Med. 2007:49(6):641-50.

5. Magnavita N. Work-related symptoms in indoor environments: a puzzling problem for the occupational physician. Int Arch Occup Environ Health. 2015:88(2):185-96

6. Saijo Y, Nakagi Y, Ito T, Sugioka Y, Endo H, Yoshida T. Dampness, food habits, and sick building syndrome symptoms in elementary school pupils. Environ Health Prev Med. 2010;15(5):276.

7. Sundell J, Levin $\mathrm{H}$, Nazaroff $\mathrm{WW}$, et al. Ventilation rates and health: multidisciplinary review of the scientific literature. Indoor Air. 2011;21(3):191-204.

8. Mentese S, Tasdibi D. Airborne bacteria levels in indoor urban environments: the influence of season and prevalence of sick building syndrome (SBS). Indoor Built Environ. 2016;25(3):563-80.

9. Zamani ME, Jalaludin J, Shaharom N. Indoor air quality and prevalence of sick building syndrome among office workers in two different offices in Selangor. Am J Appl Sci. 2013;10(10):1140.

10. Wang J, Li B, Yang Q, Yu W, Wang H, Norback D, Sundell J. Odors and sensations of humidity and dryness in relation to sick building syndrome and home environment in Chongqing, China. PLoS One. 2013;8(8):e72385.

11. Lin Z, Wang T, Norback D, Kan H, Sundell J, Zhao Z. Sick building syndrome, perceived odors, sensation of air dryness and indoor environment in Urumqi, China. Chin Sci Bull. 2014;59(35):5153-60.

12. Wolkoff $P$, Nielsen GD. Organic compounds in indoor air-their relevance for perceived indoor air quality? Atmos Environ. 2001:35(26):4407-17.

13. Cone JE, Shusterman D. Health effects of indoor odorants. Environ Health Perspect. 1991;95:53.

14. Tsai D-H, Lin J-S, Chan C-C. Office workers' sick building syndrome and indoor carbon dioxide concentrations. J Occup Environ Hyg. 2012;9(5):345-51.

15. Nur Fadilah $\mathrm{R}$, Juliana J. Indoor air quality (IAQ) and sick buildings syndrome (SBS) among office workers in new and old building in Universiti Putra Malaysia, Serdang. Health Environ J. 2012:3(2):98-109.

16. Golany GS, Ojima T. Geo-space urban design: John Wiley \& Sons; 1996. 
17. Shang Y, Li B, Baldwin AN, Ding Y, Yu W, Cheng L. Investigation of indoor air quality in shopping malls during summer in Western China using subjective survey and field measurement. Build Environ. 2016;108:1-11.

18. Cheng L, Li B, Cheng Q, Baldwin AN, Shang Y. Investigations of indoor air quality of large department store buildings in China based on field measurements. Build Environ. 2017;118:128-43.

19. Seoul Medical Center. Report of effects of indoor air pollutant influence the human body in underground commercial space in Seoul; 2017.

20. Seoul metropolitan facilities management corporation. Overview of underground walkway \& shopping center; 2017. http://www.sisul.or.kr/ open_content/undershop/guide/summary.jsp. Accessed 1 Jan 2018.

21. Korean occupational safety and Health Research Institute. Guideline development for evaluation and Management of Office air Quality (I). Korean occupational safety and Health Research Institute; 2004.

22. Bu Z, Wang L, Weschler LB, Li B, Sundell J, Zhang Y. Associations between perceptions of odors and dryness and children's asthma and allergies: a cross-sectional study of home environment in Baotou. Build Environ. 2016; 106:167-74.

23. Sundell J, Lindvall T. Indoor air humidity and sensation of dryness as risk indicators of SBS. Indoor Air. 1993;3(4):382-90.

24. Hong W, Meng M, Xie J, Gao D, Zeng Y, Ai H, Chen C, Huang S, Zhou Z. Investigation of the pollution level and affecting factors of formaldehyde in typical public places in Guangxi. China Aerosol Air Qual Res. 2017;17(11): 2816-28+a38

25. Tao H, Fan Y, Li X, Zhang Z, Hou W. Investigation of formaldehyde and TVOC in underground malls in Xi'an, China: concentrations, sources, and affecting factors. Build Environ. 2015;85:85-93.

Ready to submit your research? Choose BMC and benefit from:

- fast, convenient online submission

- thorough peer review by experienced researchers in your field

- rapid publication on acceptance

- support for research data, including large and complex data types

- gold Open Access which fosters wider collaboration and increased citations

- maximum visibility for your research: over $100 \mathrm{M}$ website views per year

At $\mathrm{BMC}$, research is always in progress.

Learn more biomedcentral.com/submissions 